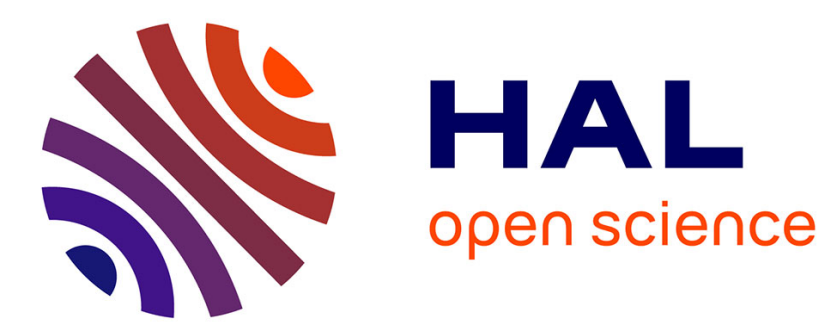

\title{
Implementation of Industry 4.0 in Germany, Brazil and Portugal: Barriers and Benefits
}

\author{
Walter C. Satyro, Mauro De Mesquita Spinola, Jose B. Sacomano, Márcia \\ Silva, Rodrigo Franco Gonçalves, Marcelo Paula Pessoa, Jose Celso Contador, \\ Luciano Schiavo
}

\section{To cite this version:}

Walter C. Satyro, Mauro De Mesquita Spinola, Jose B. Sacomano, Márcia Silva, Rodrigo Franco Gonçalves, et al.. Implementation of Industry 4.0 in Germany, Brazil and Portugal: Barriers and Benefits. IFIP International Conference on Advances in Production Management Systems (APMS), Sep 2019, Austin, TX, United States. pp.323-330, 10.1007/978-3-030-29996-5_37 . hal-02460453

\section{HAL Id: hal-02460453 https://hal.inria.fr/hal-02460453}

Submitted on 30 Jan 2020

HAL is a multi-disciplinary open access archive for the deposit and dissemination of scientific research documents, whether they are published or not. The documents may come from teaching and research institutions in France or abroad, or from public or private research centers.
L'archive ouverte pluridisciplinaire HAL, est destinée au dépôt et à la diffusion de documents scientifiques de niveau recherche, publiés ou non, émanant des établissements d'enseignement et de recherche français ou étrangers, des laboratoires publics ou privés. 


\title{
Implementation of Industry 4.0 in Germany, Brazil and Portugal: Barriers and Benefits
}

\author{
Walter C. Satyro ${ }^{1[0000-0002-0201-222 X]}$, Mauro de Mesquita Spinola ${ }^{1[0000-0002-5147-9395]}$, Jose \\ B. Sacomano ${ }^{\text {[0000-0002-4877-3139], Márcia Terra da Silva }}{ }^{2[0000-0002-5314-4978]}$, Rodrigo \\ Franco Gonçalves ${ }^{1,2[0000-0003-2206-3136]}$, Marcelo Schneck de Paula Pessoa ${ }^{1[0000-0002-8477-}$ \\ ${ }^{8543]}$, Jose Celso Contador ${ }^{3[0000-0002-7952-774 X]}$, Jose Luiz Contador ${ }^{4(0000-0002-7952-774 X)}$, and \\ Luciano Schiavo ${ }^{1[0000-0001-8299-7227]}$ \\ ${ }^{1}$ Polytechnic School of USP - Universidade de Sao Paulo, Production Engineering Research, \\ Av. Prof. Luciano Gualberto, 1380 - Butanta, São Paulo - SP, 05508-010, Brazil, \\ satyro.walter@gmail.com; mauro.spinola@poli.usp.br; \\ rofrancodosite.com.br; mpessoa@usp.br; luckschiavo@yahoo.com.br \\ ${ }^{2}$ UNIP - Universidade Paulista, Postgraduate Program in Production Engineering, Rua Dr. Ba- \\ celar, 1212, Sao Paulo, SP, Brazil, 04026-000, \\ jbsacomano@gmail.com; marcia.terra@uol.com.br \\ ${ }^{3}$ UNIP - Universidade Paulista, Postgraduate Program in Administration, \\ celsocontadoreterra.com.br \\ ${ }^{4}$ FACCAMP - Faculdade Campo Limpo Paulista, Postgraduate Program in Administration \\ jluiz@feg.unesp.br
}

\begin{abstract}
Industry 4.0 is a subject that has attracted the interests of researches worldwide for its ability to achieve productivity gains and to provide competitiveness to the companies. Although much research has been done on technical studies, little attention has been paid to the challenges that decision-makers, executives and managers face to implement the concepts of Industry 4.0 in their companies. This research was based on secondary data, involving a research made with 246 companies in Brazil, 287 in Germany and 72 in Portugal, which studied the internal and external obstacles and expectations of these 605 companies. The originality and practical implication of this research is to compare these three countries, studying common and different points to implement the concepts of Industry 4.0, so researchers can conduct their studies to try to provide answers to practical expectations, linking research to practice.
\end{abstract}

Keywords: Barriers, Industry 4.0, Strategy, Implantation.

\section{Introduction}

There has been a substantial increment in scientific publication on Industry 4.0 [1], attracting the interest of researchers from all over the world [2] by its capacity to provide flexibility and practical reconfigurable manufacturing systems, making possible mass customization processes $[3,4]$. 
Industry 4.0, the Digital transformation of the company, or the Digital manufacture, the new production paradigm [5,6], is based on interconnectivity, in which the important is the Internet, not only the computer [7,8], so the production line can exchange information and data online with supply chain, customers and other important stakeholders $[9,10]$.

Industry 4.0 was made possible by the integration of Information Technology (IT) and Automation Technology (AT) with Production supported by high technology, so humans and machines can interact with each other, bringing new possibilities to the companies to improve productivity and competitiveness.

The aim of Industry 4.0 is to generate value, establishing new business models, services and products, solving problems and increasing competitiveness by the interconnection of the internal and external environment of the companies [11 - 13].

The objective of this study is to analyze the barriers and benefits that decision-makers, executives and managers from Germany, Brazil and Portugal face to implement the concepts of Industry 4.0 on their companies.

\section{$2 \quad$ Literature Review}

\subsection{Barriers}

A barrier can be defined as any system, operational organization or technical solution that minimizes the probability of occurring events and thus limits the consequences of such events [14].

A barrier can be understood as regulatory activities put in place to avoid loss of technical integrity or reduce possible consequences [15].

\subsection{Benefits}

Benefit has different concepts, which vary according to the perspective of analysis.

Benefit can be understood as something that provides gains, advantages, is helpful, convenient or brings good effect or something of value [16, 17], a positive result obtained by an action $[18,19]$.

\subsection{Digitization and Industry 4.0}

Digitalization is the introduction of Internet-connected digital applications and technologies by companies, impacting relationship in a business network and the way value is created [20]. Digitalization is the adoption of IT-based solutions using the Internet predominantly [20]. Industry 4.0 and industrial digitalization are considered synonyms, being digitalization defined as the actions necessary to implement the concepts of Industry 4.0 [21]. The technologies that support the concepts brought by Industry 4.0 can create intelligent systems that can reduce risks, lead time, costs, but the barriers to implement it can be enormous [22], and many companies are struggling to see the challenges and opportunities in relation to digital transformation [23]. 


\section{Method}

We used secondary data provided by a series of researches made by Siemens AG [24, $25,26]$ in Germany, Brazil and Portugal about digitalization. The focus was to identify problems and expectations that decision-makers, executives and managers faced to implement the concepts of Industry 4.0 in their companies, the digital transformation of the companies, or the Digital manufacture.

The surveys were conducted in companies of all sizes and from all types of industries between 2014 and 2015, and no other recent surveys have been published so far from these countries by Siemens AG.

The surveys carried out among Siemens customers had also the intention to try to understand the complexity that digital transformation represents in the daily life of the companies.

Although the questionnaires were intended to be standardized, they had some differences among them, which made it impossible to take full advantage of them, so some parts had to be excluded for comparison and some parts had to be adapted.

\section{$4 \quad$ Results and Discussion}

Table 1 presents the size of the companies per county, which shows that except in Portugal, the majority of the 605 companies that collaborated with the surveys were of large size. Large companies were considered the ones with over 500 employees.

Table 1. Size of the companies involved in the survey.

\begin{tabular}{|c|c|c|c|}
\hline Country & Large companies & Small and medium sized & Total of respondents \\
\hline Brazil & 177 & 69 & 246 \\
\hline Germany & 151 & 136 & 287 \\
\hline Portugal & 11 & 61 & 72 \\
\hline
\end{tabular}

Table 2 shows the position of the respondents, which presents that in Germany the majority of the respondents where from middle management. In Brazil and Portugal the number of top and middle managers were almost equilibrated. Portugal presented the great majority of the respondents from the C-level position.

Table 2. Position of the respondents.

\begin{tabular}{|c|c|c|c|}
\hline Country & Top management & Middle management & C-level position \\
\hline Brazil & $40 \%$ & $44 \%$ & $16 \%$ \\
\hline Germany & $29 \%$ & $58 \%$ & $13 \%$ \\
\hline Portugal & $30 \%$ & $29 \%$ & $41 \%$ \\
\hline
\end{tabular}

In Brazil industries from 21 sectors of the economy participated of the survey, being $16 \%$ Automotive, $13 \%$ Power utilities, $11 \%$ Power transmission, $8 \%$ Minerals \& Mining, and others. In Germany the survey involved 30 sectors of the economy, but the 
sector and the percentage was not informed, and in Portugal the number of the sectors was not presented.

Participants were asked if they already had developed a structured digital strategy, whose results were displayed in Fig. 1. Curiously, the majority of affirmative answers were received by companies from Brazil (43\%), followed by Portugal (35\%), and Germany (19\%). The majority of German companies (43\%) informed that they do not have a digital strategy formulated, followed by Portuguese (33\%) and Brazilian ones (29\%).

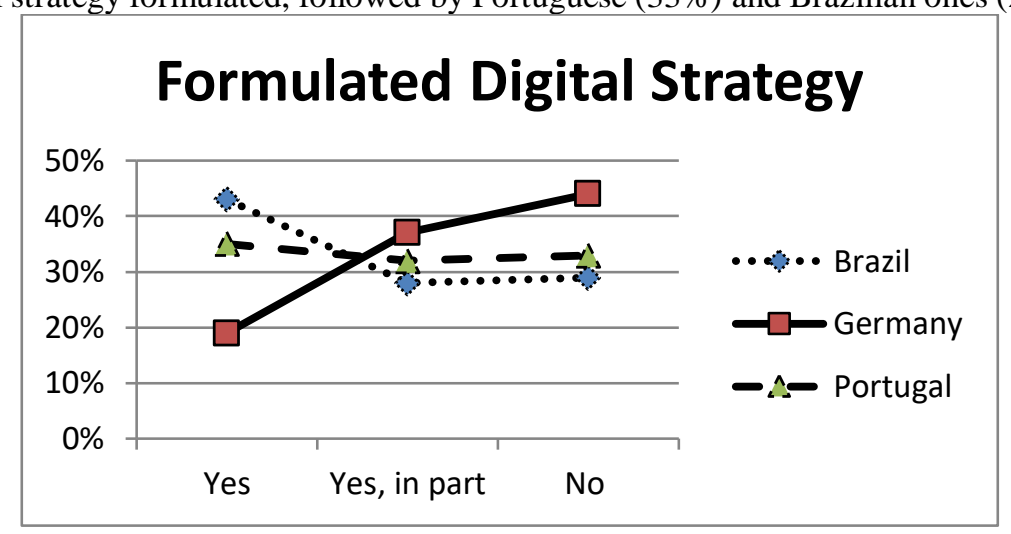

Fig. 1. Developed a structured digital strategy.

The majority of the companies from these three countries informed that the responsible for the implementation of the digital strategy was IT and/or IT \& other departments, as illustrated in Fig. 2.

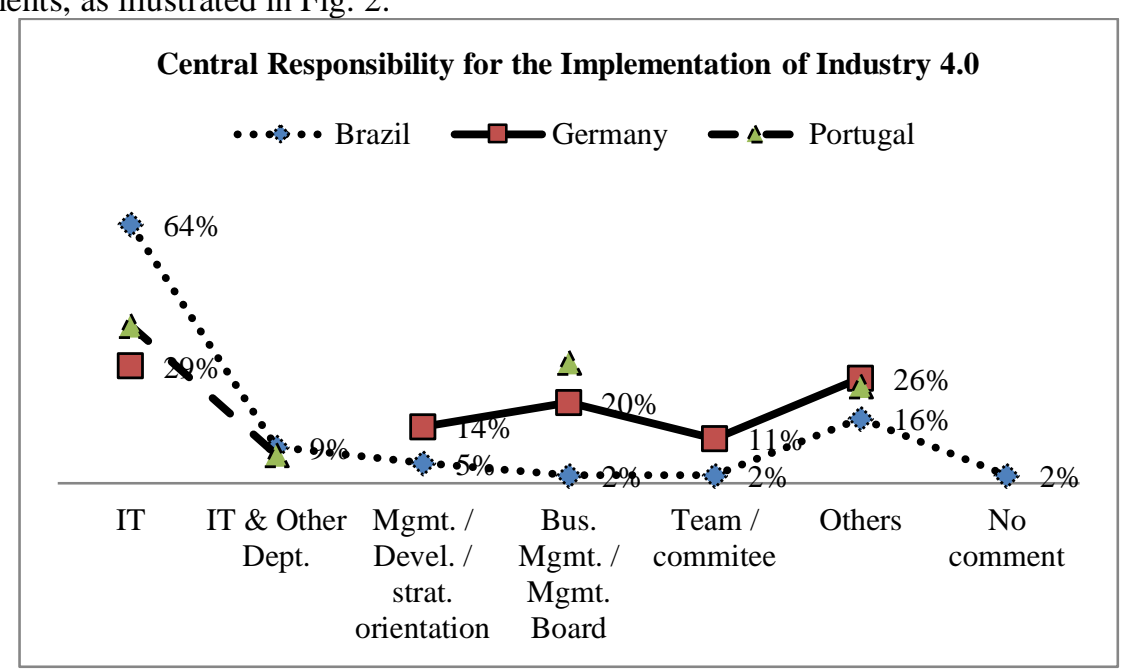

Fig. 2. Central responsibility for the implementation of Industry 4.0.

It is worth mentioning that the implementation process of the concepts of Industry 4.0 in the company is a complex task that must be managed by the top executives, like 
the ISO 9000 standards, and other important projects. Delegate to IT a task of this magnitude represents a serious risk to the whole company, and showed that the top managers interviewed by this occasion did not have the understanding of the necessary changes in structure and strategy to implement the concepts of Industry 4.0.

The respondents were asked about the challenges faced to implement the concepts of Industry 4.0 mentioned in the report (survey) as internal and external barriers. The internal barriers were presented in Table 3. Since companies could report more than one option, the sum can give greater than $100 \%$.

Table 3. Internal challenges to implement the concepts of Industry 4.0.

\begin{tabular}{|l|l|l|l|}
\hline Internal challenges & $\begin{array}{l}\text { Bra- } \\
\text { zil }\end{array}$ & $\begin{array}{l}\text { Ger- } \\
\text { many }\end{array}$ & $\begin{array}{l}\text { Portu- } \\
\text { gal }\end{array}$ \\
\hline Company structure/culture & $57 \%$ & $31 \%$ & $46 \%$ \\
\hline High operating costs (licenses and software updates) & $53 \%$ & $36 \%$ & $64 \%$ \\
\hline $\begin{array}{l}\text { Unclear benefits (lack of economic feasibility study, } \\
\text { etc.) }\end{array}$ & $52 \%$ & $41 \%$ & $46 \%$ \\
\hline Financing of technologies / software & $42 \%$ & $32 \%$ & $64 \%$ \\
\hline Costs for further education / training & $48 \%$ & $(*)$ & $57 \%$ \\
\hline
\end{tabular}

(*) not reported

Brazilian companies informed that the structure and culture of the companies were the biggest internal barrier, followed by high operating costs (licenses, software and their updates). Germany companies reported that unclear benefits (lack of economic feasibility studies, etc.) represented the biggest internal barrier, followed by high operating costs and the necessity of financing the technologies and software. Portuguese companies informed the high operating costs and the necessity of financing the technologies and software representing the biggest internal barriers, followed by costs of further education / training.

The challenges represented by external barriers to implement the concepts of Industry 4.0 are shown in Table 4 . Once again the sum can be more than $100 \%$ as multiple options are possible.

Table 4. External challenges to implement the concepts of Industry 4.0.

\begin{tabular}{|l|l|l|l|}
\hline External challenges & Brazil & Germany & Portugal \\
\hline Discussions related to data security & $55 \%$ & $39 \%$ & $38 \%$ \\
\hline No tax advantage for the investments & $52 \%$ & $(*)$ & $57 \%$ \\
\hline Lack of technical standardization & $45 \%$ & $46 \%$ & $50 \%$ \\
\hline No demand from customers or suppliers & $33 \%$ & $35 \%$ & $38 \%$ \\
\hline
\end{tabular}

(*) not reported

Brazilian companies reported that data security was considered the main external barrier, followed by no tax advantage for the investments.

Germany companies revealed that the lack of technical standardization was the predominant concern, followed by data security and the lack of demand for Industry 4.0 
from customers or suppliers. Portuguese companies informed that the principal external barrier was the absence of tax advantage for the investments, followed by the lack of technical standardization and data security.

\subsection{Comparison of results}

The majority of the respondents in Brazil and Portugal reported that they already had a structured strategy to implement the concepts of Industry 4.0, differently from Germany, where the majority informed that such strategy was lacking. In the accumulated of these three countries the respondents informed that they do not have a solid digital strategy.

These three countries had in common to delegate to IT the central responsibility for the implementation of Industry 4.0, not assessing the consequences of this decision. In total, the respondents of Brazil, Germany and Portugal see as main internal challenges the necessity of expensive investments in operating costs to implement the concepts of Industry 4.0 , followed by the unclear benefits or lack of economic feasibility studies to guide the investments and the necessity of financing technologies / software required. Only in Brazil it was mentioned the absence of support from top management as an internal challenge.

The lack of technical standardization was reported as the main external challenge in these three countries, followed by the necessity of improvement of data security and the absence of tax advantage for the investments. The respondents in Brazil and Portugal informed that they feared competitors from other industries could be faster in the implementation process, and also that in these two countries they had not found the right partner to help them in this process.

These respondents hoped that Industry 4.0 could increase resource and energy efficiency, increase service processes, enhance decision making, provide greater transparency in business processes, strength synergies and / or collaboration, and be guided by a stronger orientation towards the customer.

\section{Conclusion}

This study involved 605 companies from three countries: Germany, Brazil and Portugal, which participated of a survey made by Siemens AG in order to evaluate the expectations and difficulties that these companies faced to implement Industry 4.0 or the Industrial digitalization concepts.

Although the research may appear old (Germany, 2014, Brazil 2015, and Portugal 2015), a limitation of this study, it is useful in terms of comparing three different countries with the common goal of implementing the concepts of Industry 4.0 in close time, and also see that some challenges still persists.

As internal challenges, the respondents of these three countries were afraid of having to invest in new operation lines, technology financing, culture / structure change, among others, not seeing clear economic benefits. Regarding the external challenges or 
barriers mentioned, there was the lack of technical standardization and data security. Despite the progress in these areas, the problem persists to this day.

The concepts of Industry 4.0 can help companies to increase international competitiveness in order to be more active and relevant on global markets to achieve important progress toward superior levels of competitiveness; however, for doing so, decisionmakers, executives and managers will face obstacles, risks, barriers but also opportunities and benefits. It is not an easy task, since it may be necessary to change structure or strategy, or both, involving high-magnitude restructurings in the middle of an environment full of uncertainties.

We hope the main challenges, or internal and external barriers of this study, can serve as a basis for future researches or special Congresses sections, so that academic studies can provide answers to relevant practical expectations, linking research to practice, where both win.

\section{References}

1. Klotzer, C., Weibenborn, J., Pflaum, A.: The Evolution of Cyber-Physical Systems as a Driving Force behind Digital Transformation. Proceedings - 2017 IEEE 19th Conference on Business Informatics, CBI 2017, 5-14 (2017).

2. Schneider, P.: Managerial challenges of Industry 4.0: an empirically backed research agenda for a nascent field. Review of Managerial Science 12(3), 803-848 (2018).

3. Pasetti Monizza, G., Rojas, R.A., Rauch, E., Garcia, M.A.R., Matt, D.T.: A case study in learning factories for real-time reconfiguration of assembly systems through computational design and cyber-physical systems. IFIP Advances in Information and Communication Technology 540, 227-237 (2018).

4. Simon, J., Trojanova, M., Zbihlej, J., Sarosi, J.: Mass customization model in food industry using industry 4.0 standard with fuzzy-based multi-criteria decision making methodology. Advances in Mechanical Engineering 10(3) (2018).

5. Galvão, J., Sousa, J., Machado, J., Mendonça, J., Machado, T., Silva, P.V.: Mechanical design in industry 4.0: Development of a handling system using a modular approach. In: Machado J., Soares F., Veiga G. (eds) Innovation, Engineering and Entrepreneurship. HELIX 2018. Lecture Notes in Electrical Engineering, vol 505. Springer, Cham, 508-514 (2019).

6. Modrak, V., Soltysova, Z., Poklemba, R.: Mapping requirements and roadmap definition for introducing I 4.0 in SME environment. In: Hloch S., Klichová D., Krolczyk G., Chattopadhyaya S., Ruppenthalová L. (eds) Advances in Manufacturing Engineering and Materials. Lecture Notes in Mechanical Engineering. Springer, Cham 183-194 (2019).

7. Plattform Industrie $4.0 \quad$ (2016), https://www.plattform-i40.de/I40/Navigation/EN/Home/home.html, last accessed 2019/01/10.

8. Lopez, H.A.G., Cisneros, M.A.P.: Industry 4.0 \& Internet of things in supply chain. In: CLIHC 17 Proceedings of the 8th Latin American Conference on Human-Computer Interaction, Article No. 23 (2017).

9. Choi, S. S., Kang, G., Jung, K., Kulvatunyou, B., Morris, K.C.: Applications of the factory design and improvement reference activity model. In: I. A. Nääs et al. (Eds.) IFIP 2016: APMS 2016 (2016).

10. Wiesner, S., Hauge, J.B., Thoben, K-D.: Challenges for requirements engineering of cyberphysical systems in distributed environments. In: S. Umeda et al. (Eds.) APMS 2015, Part II, IFIP AICT 460, pp. 49-58 (2015). doi: 10.1007/978-3-319-22759-7_6 
11. Kang, H. S., Lee, J. Y., Choi, S-S, Kim, H., Park, J. H., Son, J. Y., Kim, B. H., Noh, S. D.: Smart manufacturing: Past research, present findings, and future directions. Intl. J. of Precision Engineering and Manufacturing-Green Technology, 3(1), 111-128 (2016).

12. Hermann, M., Pentek, T., Otto, B.: Design principles for industrie 4.0 scenarios: A literature review. In: Working Paper No. 01 / 2015, Technische Universität Dortmund, Fakultät Maschinenbau and Audi Stiftungslehrstuhl - Supply Net, Order Management, 1-15 (2015).

13. Sanders, A., Elangeswaran, C., Wulfsberg, J.: Industry 4.0 implies lean manufacturing: research activities in industry 4.0 function as enablers for lean manufacturing. Journal of Industrial Engineering and Management, 811-833 (2016).

14. Bento, J.-P. : Review from an MTO-perspective of five investigation reports from BP (Draft). Norway: Stavanger (2003).

15. Purton, L., Clothier, R., Kourousis, K., Massey, K.: The PBP Bow-Tie framework for the systematic representation and comparison of military aviation regulatory frameworks. The Aeronautical Journal 118(1210), 1433-1452 (2014).

16. Kim, M.J., Bonn, M., Lee, C.-K.: Seniors' dual route of persuasive communications in mobile social media and the moderating role of discretionary time. Asia Pacific Journal of Tourism Research 22(8), 799-818 (2017).

17. Coombs, C.R.: When planned IS/IT project benefits are not realized: A study of inhibitors and facilitators to benefits realization. International Journal of Project Management 33(2), 363-379 (2015).

18. Yoshikawa, M., Shimizu, T.: A new ranking scheme and result representation for XML information retrieval based on benefit and reading effort. In: Proceedings - International Conference on Informatics Education and Research for Knowledge-Circulating Society, ICKS 2008 4460473, 87-92 (2008).

19. Adams, R.M.: Issues in assessing the economic benefits of ambient ozone control: Some examples from agriculture. Environment International 9(6), 539-548 (1983).

20. Pagani, M., Pardo, C.: The impact of digital technology on relationships in a business network. Industrial Marketing Management 67, 185-192 (2017).

21. Schluter, F., Hetterscheid, E.: A Simulation Based Evaluation Approach for Supply Chain Risk Management Digitalization Scenarios. In: 2017 International Conference on Industrial Engineering, Management Science and Application, ICIMSA 20177985579 (2017).

22. Lowenstein, D., Slater, C.: Management of Test Utilization, Optimization, and Health through Real-Time Data. AUTOTESTCON (Proceedings). September,8532554 (2018).

23. Bienhaus, F., Haddud, A.: Procurement 4.0: factors influencing the digitisation of procurement and supply chains. Bus. Process Management Journal. 24(4), 965-984 (2018).

24. Siemens AG: Germany 2014 Digitalization - Siemens Customer Survey | Result Report, 118 (2015).

25. Siemens AG: Digitalization - Trends and Solutions for a More Competitive Brazil 2015 Siemens Customer Survey | Result Report, 1-24 (2015).

26. Siemens AG: Digitalization - Trends and Solutions for a More Competitive Portugal 2015 Siemens Customer Survey | Result Report, 1-23 (2016). 